\title{
Fatal Iron Toxicity in an Adult: Clinical Profile and Review
}

\author{
Mandar Ramachandra Sane, Kamal Malukani' ${ }^{1}$ Rashmi Kulkarni², Abhishek Varun² \\ Department of Forensic Medicine and Toxicology, Government Medical College and Hospital, Chandigarh, Departments of ${ }^{1}$ Pathology and ${ }^{2}$ Forensic Medicine and \\ Toxicology, Sri Aurobindo Medical College and PGI, Indore, Madhya Pradesh, India
}

\section{Abstract}

Acute iron toxicity is usually seen in children with accidental ingestion of iron-containing syrups. However, the literature on acute iron toxicity with suicidal intent in adults is scant. We report an instance wherein an adult committed suicide by ingestion of multiple iron tablets. Delay in treatment was there due to misdiagnosis of the intoxicating agent. She developed fulminant hepatic failure with rapid clinical deterioration. Despite aggressive supportive management, the patient succumbed to the toxic doses of iron. Clinical course and postmortem features are discussed with a review of the literature.

Keywords: Ferrous sulfate, hepatic failure, Perl's stain, toxidrome

\section{INTRODUCTION}

Iron is the most abundant trace element in the body and is essential in most biological systems. ${ }^{[1]}$ Iron is an intracellular poison, and it exerts its toxic effect on mitochondria by shunting electrons away from the electron transport chain, uncoupling the oxidative phosphorylation, thus leading to anaerobic metabolism. ${ }^{[2]}$ Iron poisoning in an adult is uncommon. Most of the cases of iron poisoning reported in literature are of pediatric age group, ${ }^{[2-4]}$ while only four cases $^{[1,5,6]}$ were of older age group.

In this article, we present a case of acute iron intoxication in a 20-year-old female who was misdiagnosed as aluminum phosphide poisoning and subsequently managed as iron poisoning. Clinical symptoms, laboratory tests, institutional toxicology screening, and histopathology which corresponded with severe iron intoxication are discussed.

\section{Case Report}

A 20-year-old female allegedly consumed some tablets with suicidal intention. She initially presented at primary health center with abdominal pain, vomiting, diarrhea, and shock. As the intoxicating agent was not clear, treatment was started for aluminum phosphide poisoning as it is quite prevalent in the area. Initial complete blood count and serum electrolytes were unremarkable. The patient's condition deteriorated

\begin{tabular}{|l|l|}
\hline \multicolumn{3}{|c|}{ Access this article online } \\
\hline Quick Response Code: & Website: \\
\hline & www.ijccm.org \\
\hline
\end{tabular}

and she was referred to our hospital on the $3^{\text {rd }}$ day. At our hospital, she was further investigated; hemoglobin was $9.1 \mathrm{~g} / \mathrm{dl}$ and total white blood cell count was $11,900 /$ cumm. Liver function tests showed marked elevation in the liver enzymes (aspartate aminotransferase [AST] - 404 IU/L and alanine aminotransferase [ALT] - $1982 \mathrm{IU} / \mathrm{L})$. Other investigations showed total bilirubin $-6.37 \mathrm{mg} / \mathrm{dL}$, direct bilirubin $4.60 \mathrm{~nm} / \mathrm{dL}$, indirect bilirubin $-1.77 \mathrm{mg} / \mathrm{dL}$, total protein $6.43 \mathrm{~g} / \mathrm{dL}$, serum albumin $-3.35 \mathrm{~g} / \mathrm{dL}$, alkaline phosphatase $112 \mathrm{IU} / \mathrm{L}$, and amylase - $465 \mathrm{U} / \mathrm{L}$. Prothrombin time was 56 with international normalized ratio of 5.7. Silver nitrate test was negative for phosphide. Her detailed history was sought again, in which she revealed consumption of many ferrous sulfate tablets. Hematic profile showed serum iron levels as $185 \mu \mathrm{g} / \mathrm{dl}$, serum ferritin - $692 \mathrm{ng} / \mathrm{dl}$, total iron binding capacity $-90 \mu \mathrm{g} / \mathrm{dl}$, and percentage saturation $-2 \%$. Blood gas analysis showed severe metabolic acidosis. Chelation therapy with desferrioxamine was started, and supportive measures were continued. However, her clinical condition deteriorated further, and she died within $48 \mathrm{~h}$ of admission due to multiorgan failure.

Address for correspondence: Dr. Mandar Ramachandra Sane, Department of Forensic Medicine and Toxicology, Government Medical College and Hospital, Chandigarh - 160 030, India. E-mail: drmrsane@hotmail.com

This is an open access journal, and articles are distributed under the terms of the Creative Commons Attribution-NonCommercial-ShareAlike 4.0 License, which allows others to remix, tweak, and build upon the work non-commercially, as long as appropriate credit is given and the new creations are licensed under the identical terms.

For reprints contact: reprints@medknow.com

How to cite this article: Sane MR, Malukani K, Kulkarni R, Varun A. Fatal iron toxicity in an adult: Clinical profile and review. Indian J Crit Care Med 2018;22:801-3. 


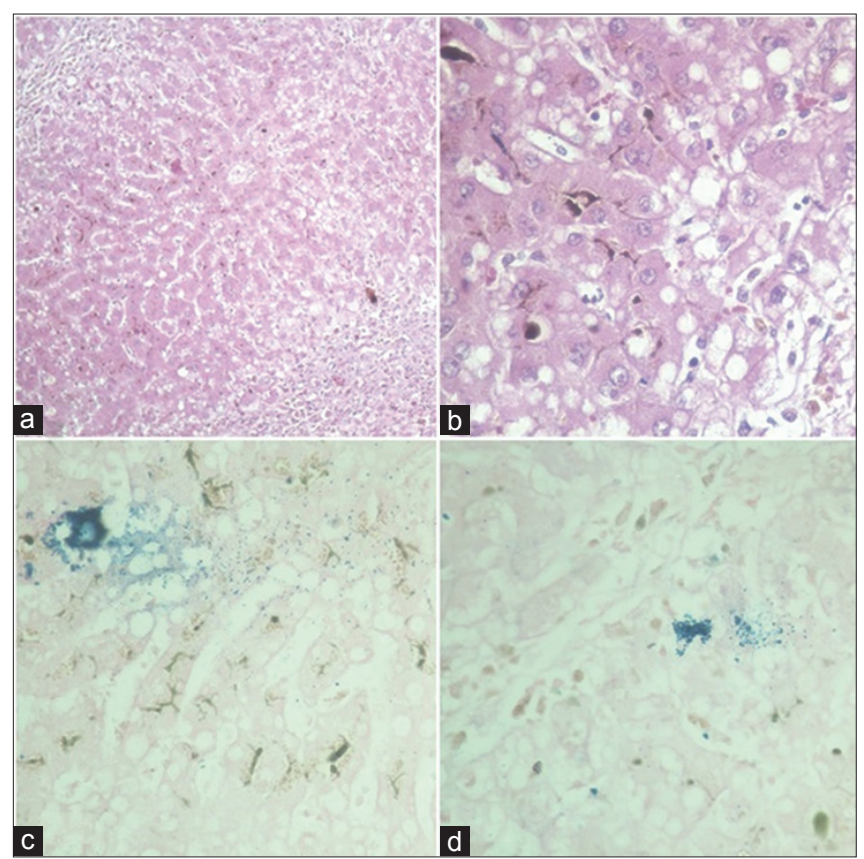

Figure 1: Photomicrographs showing (a) liver parenchymal tissue with periportal necrosis ( $\mathrm{H}$ and $\mathrm{E}, \times 40)$; (b) deposition of golden brown pigment in cytoplasm of hepatocytes and sinusoids with cholestasis in bile canaliculi ( $\mathrm{H}$ and $\mathrm{E}, \times 400)$; ( $\mathrm{C}$ and $\mathrm{d}$ ) granular blue deposits of iron in and outside the hepatocytes (Perl's, $\times 100$ )

Autopsy revealed enlarged liver. Histopathology showed periportal necrosis and bile cholestasis [Figure 1a and b]. Other organs were unremarkable on routine hematoxylin and eosin stain. On Perl's stain, iron deposits were noted in the liver, lungs, and spleen, suggestive of iron overload [Figures 1c, $d$ and 2]. Cause of death was attributed to multiorgan failure due to iron poisoning.

\section{Discussion}

The present case discusses delayed clinical presentation of iron toxicity. Iron toxicity has five clinical stages. These stages of clinical course may not be found in all patients, and in cases of massive overdose, the patient may present in shock ${ }^{[7]}$ Rapidly progressive clinical course from Stage I to Stage III was also observed in reported cases, ${ }^{[4]}$ and this may cause potential misdiagnosis when history is not clear.

Unreliability is inherent in overdose or poisoning histories as was in the present case. In the present case, initial history was misleading and the patient was treated for aluminum phosphide poisoning, as it is quite prevalent in this part of the country ${ }^{[8]}$ and has similar toxidrome as that of acute iron toxicity. Toxicology screening for phosphide was negative, leading to re-interview of the patient which revealed consumption of multiple iron tablets. Although misdiagnosis of the intoxicating agent was corrected, delay in the treatment of iron toxicity leads to adverse clinical outcome. Patients are reported to have better outcome and survival if they present early and are managed with desferrioxamine, bowel irrigation, and other supportive treatment.

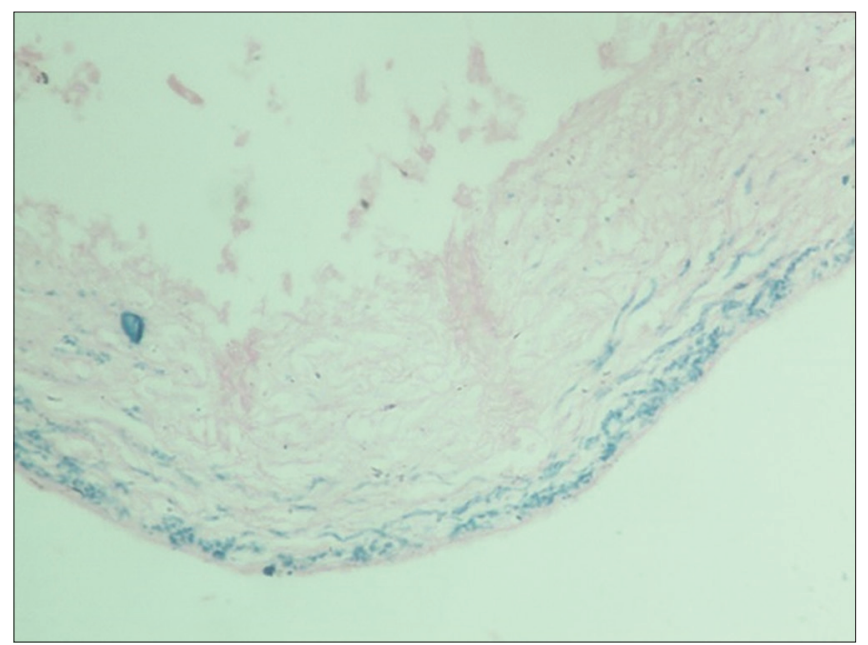

Figure 2: Photomicrograph showing granular blue deposits of iron in the splenic parenchyma (Perl's, $\times 100$ )

In the present case, it was not clear as to how many iron tablets patient had consumed, and hence, calculation of total iron ingested was not possible. If the patient presents early, then serum iron concentration of $300 \mathrm{mcg} / \mathrm{dL}$ or above can present as moderate toxicity, while serum iron concentration of $500 \mathrm{mcg} / \mathrm{dL}$ or above represents severe toxicity. ${ }^{[6]}$ Serum iron levels are best estimated within $2-6 \mathrm{~h}^{[9,10]}$ as rapid distribution of iron from circulation to tissues results in stabilization of iron levels. ${ }^{[9]}$ Hence, diagnosis was not confirmed by serum iron levels where presentation was after $36 \mathrm{~h}^{[9]}$ and $48 \mathrm{~h} .{ }^{[1]}$ Other parameters which showed positive correlation with elevated serum iron and hence severe toxicity include severe vomiting or diarrhea, shock, coma, coagulopathy, metabolic acidosis, hyperglycemia, and leukocytosis. ${ }^{[2]}$ Our patient had iron levels of $185 \mathrm{IU} / \mathrm{L}$ after $48 \mathrm{~h}$ of ingestion, raised AST/ALT levels, deranged liver function tests, coagulopathy, and state of shock indicating severe toxicity.

Hepatotoxicity is known sequela of iron poisoning and is associated with $50 \%$ of mortality. ${ }^{[5]}$ It is found to be dose dependent ${ }^{[11]}$ and hence useful in cases which present late, as serum iron levels may not be a reliable prognostic indicator in such cases. In the present case, hepatic toxicity was manifested by periportal necrosis and cholestasis. Coagulative degeneration, shrinkage of hepatocytes, intense cytoplasmic eosinophilia, and karyorrhexis are also reported ${ }^{[4]}$ In the present case, Perl's-stained iron deposits were found in hepatocytes. However, pigment did not attribute to "alcoholic iron" as liver was noncirrhotic and deceased was nonalcoholic. ${ }^{[12]}$

\section{ConcLusion}

As suicidal iron tablets overdose is uncommon, it can be misdiagnosed with toxicity by the agent having a similar clinical outcome. However, toxicological assistance to an intensivist is vital in such cases as it rules out concomitant intoxication or intoxication by an agent having similar toxidrome and fatality due to delay in treatment of iron toxicity can be prevented. 


\section{Declaration of patient consent}

The authors certify that they have obtained all appropriate patient consent forms. In the form the patient(s) has/have given his/her/their consent for his/her/their images and other clinical information to be reported in the journal. The patients understand that their names and initials will not be published and due efforts will be made to conceal their identity, but anonymity cannot be guaranteed.

\section{Financial support and sponsorship}

Nil.

\section{Conflicts of interest}

There are no conflicts of interest.

\section{ReFERENCES}

1. Abhilash KP, Arul JJ, Bala D. Fatal overdose of iron tablets in adults. Indian J Crit Care Med 2013;17:311-3.

2. Baranwal AK, Singhi SC. Acute iron poisoning: Management guidelines. Indian Pediatr 2003;40:534-40.

3. Singhi SC, Baranwal AK, M J. Acute iron poisoning: Clinical picture, intensive care needs and outcome. Indian Pediatr 2003;40:1177-82.

4. Pestaner JP, Ishak KG, Mullick FG, Centeno JA. Ferrous sulfate toxicity: A review of autopsy findings. Biol Trace Elem Res 1999;69:191-8.

5. Mahesh K, Rani R. A case of iron poisoning- case report. Int J Basic Appl Med Sci 2014;4:101-3.

6. Geraci MJ, Heagney H. Iron overdose during pregnancy: Case and treatment review. Int J Clin Med 2012;3:715-21.

7. Pillay VV. Modern Medical Toxicology. $4^{\text {th }}$ ed. New Delhi: Jaypee Brothers Medical Publishers; 2013. p. 97.

8. Mishra PK, Kulkarni R, Sane MR, Deshpande A, Kushwah M. Prospects of poisoning - A multi facet study. Arch Med Sadowej Kryminol 2016;66:235-43.

9. Skoczynska A, Kwiecinska D, Kielbinski M, Lukaszewski M. Acute iron poisoning in adult female. Hum Exp Toxicol 2007;26:663-6.

10. Tenenbein M. Toxicokinetics and toxicodynamics of iron poisoning. Toxicol Lett 1998;102-103:653-6.

11. Robertson A, Tenenbein M. Hepatotoxicity in acute iron poisoning. Hum Exp Toxicol 2005;24:559-62.

12. Dettmeyer RB. Forensic Histopathology Fundamentals and Perspectives. Berlin: Springer; 2011. p. 141. 